\title{
Operations Research - What It is all About
}

\author{
Ngutor Nyor ${ }^{1, *}$, Adamu Idama ${ }^{2}$, Omolehin J.O. ${ }^{3}$, Rauf K. $^{4}$ \\ ${ }^{1}$ Department of Mathematics/Statistics, Federal University of Technology Minna, Nigeria \\ ${ }^{2}$ Department of Operations Research, Federal University of Technology, Yola, Nigeria \\ ${ }^{3}$ Department of Mathematics, Federal University Lokoja, Nigeria \\ ${ }^{4}$ Department of Mathematics, University of Ilorin, Nigeria \\ *Corresponding Author: ngutornyor@yahoo.com
}

Copyright @ 2014 Horizon Research Publishing All rights reserved.

\begin{abstract}
This paper discusses what Operations Research (OR) is, it's historical development, the distinguishing characteristics of OR as well as it's contributions, what OR can do and the future of OR. The eventual intension behind using Operations Research (OR) is to elicit a best possible solution to a problem mathematically, which improves or optimizes the performance of the system. Operations Research attempts to provide those who manage organized systems with objective and quantitative basis for decisions. OR is the application of science to the solution of managerial and administrative problems, and it focuses on the performance of organized systems taken as a whole rather than on their parts taken separately. It is concerned with how managerial decisions are and should be made.
\end{abstract}

Keywords Operations Research, Analytical Techniques, Interdisciplinary, Optimization, Scientific Methods, Models, Decision making, Management Problems

\section{Definitions of Operations Research}

According to wikipedia (www.wikipedia.com), "Operations Research (OR) in the U.S., and Operational Research in the U.K., is an interdisciplinary branch of applied mathematics which uses methods like mathematical modeling, statistics and algorithms to arrive at optimal or good decisions in complex problems which are concerned with optimizing the maxima or minima".

Olokoyo (2001) defines OR as the application of scientific methods to problems arising from operations involving integrated systems of people, machines and materials.

According to the OR society.com (www.theorsociety.com), "in a nut shell, OR is the discipline of applying appropriate analytical methods to help make better decisions."

www.informs.org has this to say: "OR is a community including practitioners, researchers, educators, and students; which have an ecosystem of strengths, weaknesses, opportunities and threats.
"Operations Research (OR) is the discipline of applying advanced analytical methods to help make better decisions."(www.mit.edu).

Operations Research (OR) emphasizes optimizing organizational and system performance using advanced analytical methods to help make better decisions" (www.orie.cornell.edu).

According to www.orsoc.org.uk, "OR is the application of analytical techniques to solve business problems."

"Operations Research is a technique that helps to solve a wide variety of real world problems with systems whose design or operation requires human decision making." (www.or.ncsu.edu)

According to Idama (1999), "Operations Research is the application of scientific methods to the management of organized systems."

From the above definitions, we can deduce that $\mathrm{OR}$ is the viaduct between sciences and social sciences using scientific techniques to solve managerial and human problems mathematically.

\section{Operations Research - The Science of Better}

The eventual intension behind using Operations Research is to elicit a best possible solution to a problem mathematically, which improves or optimizes the performance of the system.

"Operations Research attempts to provide those who manage organized systems with objective and quantitative basis for decisions. It is normally carried out by teams of scientists and engineers drawn from a variety of disciplines. Thus OR is the application of science to the solution of managerial and administrative problems, and it focuses on the performance of organized systems taken as a whole rather than on their parts taken separately. It is concerned with how managerial decisions are and should be made. It provides the knowledge and understanding required to make effective use of men and machines to carry it out.”(Britannica 13, p.594) 
By using techniques such as mathematical modeling to analyze complex situations, Operations Research gives executives the power to make more effective decisions and build more productive systems based on:

i. More complete data

ii. Consideration of all available options

iii. Careful predictions of outcomes and estimates of risk

iv. The latest decision tools and techniques.

\section{The Secrete of Better Decision Making in a Complex World}

The discipline of OR develops and uses mathematical and computational methods for decision-making. The field revolves around a mathematical core consisting of several fundamental topics including optimization, stochastic systems, simulation, economics and games theory, and network analysis.

The broad applicability of its core topics places OR at the heart of many important contemporary problems such as communication network management, statistical learning, supply-chain management, pricing and revenue management, finance engineering, market design, bio-informatics, production scheduling, energy and environmental policy, and transportation logistics, to name a few.

Executives in every kind of organization- large or small, private or public, profit or non-profit are using OR to unlock the value in their data, model complex systems, and make better decisions with less risk. OR helps in the following ways - Secretes of Organizational Success:

i. Improved processes, productivity and performance

ii. Insight into difficult problems

iii. Millions in cost savings and increased revenue

iv. More or better options

v. Accurate predictions, plans, and forecasts

vi. Greater market share

vii. Higher quality

viii. Better asset utilization

ix. Faster payback

x. Breakthrough efficiency

To achieve these results, OR professionals draw upon the latest analytical technologies including:

Simulation: Giving you the ability to try out approaches and test ideas for improvement

Optimization: Narrowing your choices to the very best when there are virtually innumerable feasible options and comparing them is difficult

Probability and Statistics: Helping you measure risk, mine data to find valuable connections and insights, test conclusions, and make reliable forecasts.

\section{Related Occupations}

"The term Operations Research and management science is often used synonymously" (www.wikipedia.com; Idama,
1999). When a distinction is drawn, management science generally implies a closer relationship to the problems of business management. OR also closely relates to industrial engineering. Industrial engineering takes more of an engineering point of view, and industrial engineering typically considers OR techniques to be a major part of their tool set.

Some of the primary tools used by OR are statistic, optimization, probability theory, queuing theory, game theory, graph theory, decision analysis and simulation. Because of the computational nature of these fields, OR also has close ties to computer science.

Economists, computer system analysts, mathematicians, and engineers also use advanced analysis and often apply the principles of operations research. Workers in other occupations that also stress advanced analysis include computer scientists and data base administrators, computer programmers, statisticians, market and survey researchers. Because its goal is improved organizational effectiveness, operations research also is closely allied to managerial occupations such as computer and information systems managers, and management analysts.

Worthy of note is also the view of Olokoyo (2001), "Operations Research, a term often used interchangeably with management science, began to be used in the early 1940's. Synonyms for the term Operations Research are numerous. A frequent substitute is Management Science (MS), and other terms such as System Analysis, Systems Science, Operations Analysis, Quantitative Analysis, Managerial Analysis, Management Analytical Tools (MAT), Decision Analysis, and Decision Science are all used."

\section{Historical Development of Operations Research}

Operational Research was born in response to a specific pressing military need. Just before the outbreak of World War II, Britain was concerned about the need for her to be able to defend her territories against possible air attacks from Germany. National survival was at stake. In order to tackle this problem, a number of possible solutions to this pressing problem were postulated, prominent among them was to try and develop "death rays" which might kill, incapacitate or make it impossible for $\mathrm{n}$ enemy aircraft to operate. Robert Watson-Watt was approached to organize research on this weapon. In the course of their research it became evident to the scientists that a first requirement was the development of instrument which was capable of detecting an approaching aircraft early enough to enable adequate preparation for an appropriate response. This research gave birth to what we know today as radar (Idama, 1999).

Although the military retained it's capability in Operations Research after the war, many military Operations Researchers found a strong demand for their talent in the civilian Operations Research. Ever since the end of the World War II, many large corporations and civil 
governmental organizations have created research activities dealing with operational problems in product development, marketing, transportation, ingredients mixture and so on.

According to wikipedia (www.wikipedia.com), some say that Charles Babbage (1771-1871) is the "Father of Operations Research" because his research into the cost of transportation and sorting of mail led to England's Universal "penny post" in 1840 . The modern field of OR arose during World War II. Scientists in the United Kingdom including Patrick Blackett, Cecil Gordon, C.H Waddington, Owen Wannsbrough-Jones and Frank Yates, and in the United States with George Dantziig looked for ways to make better decisions in such areas as logistics and training schedules. After the War it began to be applied to similar problems in industry.

Blackett's team made a number of crucial analyses which aided the war effort. In one piece of work, Blackett's team analyzed a report of a survey carried out by RAF Bomber Command. For the survey, Bomber Command inspected all bombers returning from bombing raids over Germany over a particular period. All damage inflicted by German air defenses was noted and the recommendation was given that armor be added in the most heavily damaged areas. Their suggestion to remove some of the crew so that an aircraft loss would result in fewer personnel loss was rejected by RAF command. Blackett's team instead made the surprising and counter-intuitive recommendation that the armor be placed in the areas which were completely untouched by damage, according to the survey. They reasoned that the survey was biased, since it only included aircraft that successfully came back from Germany. The untouched areas were probably vital areas, which if hit, would result in the loss of the aircraft. When the Germans organized their air defenses into the Kammhuber Line, it was realized that if the RAF bombers were to fly in a bomber stream they could overwhelm the night fighters who flew in individual cells directed to their targets by ground controllers. It was then a matter of calculating the statistical loss from collisions against the statistical loss from night fighters to calculate how close the bombers should fly to minimize RAF losses.

With the expanded techniques and growing awareness, $\mathrm{OR}$ is no longer limited to only operations, and the proliferation of computer data collection has relieved analysts of much of the more mundane research. But the OR analyst much still know how a system operates, and learn to perform even more sophisticated research than ever before. In every sense the name OR still applies, more than half a century later.

\section{Scope of Operations Research}

A few examples of applications in which operations research is currently used include:

- Designing the layout of a factory for efficient flow of materials.

- Constructing a telecommunications network at low cost while still guaranteeing Quality of Service (QoS) or Quality of experience (QoE) if particular connections become very busy or get damaged.

- Road traffic management and 'one way' street allocations i.e. Allocation problem.

- Determining the routes of school buses (or city buses) so that as few buses are needed as possible.

- Designing the layout of a computer chip to reduce manufacturing time (therefore reducing cost)

- Managing the flow of raw materials and products in a supply chain based on uncertain demand for the finished products

- Efficient messaging and customer response tactics

- Robotizing or automating human-driven operation processes.

- Globalizing operations process in order to take advantage of cheaper materials, labor, land or other productivity inputs.

- Managing freight transportation and delivery systems

- Scheduling

- Personnel staffing

- Manufacturing steps

- Project tasks

- Network data traffic: these are known as queuing models or queuing systems

- Sport events and their television coverage

- Blending of raw materials in oil refineries.

- Government where evidence-based policy is used.

\section{Societies and Journals}

"The International Federation of Operations Research Societies is an umbrella organization for Operations Research Societies worldwide" (www.wikipedia.com).

Significant among these are:

- Institute for Operations Research and the Management sciences (INFORMS).

- Operations Research Society

- EURO is the association for European operational Research Societies

- CORS is the Canadian Operations Research Society

- ASOR is the Australian Society for Operations Research.

- MORS is the Military Operations Research Society, based in the United States since 1966 with the objective of enhancing the quality and usefulness of military operations research analysis in support of decisions

- ORSNZ is the Operations Research Society of New Zealand

- ORSP is the Operations Research Society of the Philippines

- ORSI is the Operations Research Society of India

- ORSSA is the Operations Research Society of South Africa. 
In 2004, INFORMS began initiative to better market the OR profession, including a website entitled: The Science of Better, which provides an introduction to OR and examples of successful applications of OR to industrial problems.

\section{What Can OR Do for You?}

Many of the challenges facing organizations today are perfectly suited to the unique powers of $\mathrm{OR}$, and the kinds of results it can deliver (www.theorsociety.com).

The OR value proposition includes:

i. Business insight: Providing Quantitative and business insight into complex problems

ii. Business Performance: Improving business performance by embedding model-drive intelligence into an organizations information system to improve decision making.

iii. Cost Reduction: Finding new opportunities to decrease cost or investment.

iv. Decision Making: Accessing the likely outcomes of decision alternatives and uncovering better alternatives.

v. Forecasting: Providing a better basis for more accurate forecasting and planning.

vi. Improved Scheduling: Efficiently scheduling staff, equipment, events and more.

vii. Planning: Applying quantitative techniques to support operations, tactical planning, and strategic planning.

viii. Pricing: Dynamically pricing products and services.

ix. Productivity: helping organizations find ways to make processes and people more productive.

x. Profits: Increasing revenue or returns on investment; increasing market share.

xi. Quality: Improving quality as well as quantifying and balancing qualitative considerations.

xii. Recovery: Gaining greater control and achieving turn-around

xiii. Resources: Gaining greater utilization from limited equipment, facilities, money, and personnel.

xiv. Risk: Measuring risk quantitatively and uncovering factors critical for managing and reducing risk.

xv. Throughput: Increasing speed or throughput and decreasing delay.

\section{Distinguishing Characteristics of Operations Research}

According to Idama (1999), Operations Research can be distinguished by four major characteristics:

i. Complete disregard for Frontiers

ii. Use of scientific method

iii. Use of multidisciplinary teams, and

iv. Adaptation of the systems approach in problem solving.
Complete disregard for Frontiers: Whether in discipline or in problem area, complete disregard for frontiers is one of the great pillars on which rests the strength of OR. This vital characteristic of OR may have been a product of circumstances rather than a choice. During the war, when scientists were assigned to undertake OR for the military, there was neither regard for their disciplinary backgrounds nor for the kind of problems they were required to investigate. For example, professor P.M.S Blackett, a distinguished physicists and Nobel Laureate was in charge of the Anti aircraft command Research Group. This group included three physiologists, two mathematical physicists, an astrophysicist, an Army Officer, a former surveyor, a general physicist and two mathematicians. (R.L.A in Idama, 1999).

The range of problems these diverse scientists were required to investigate showed complete disregard for specialization.

Use of Scientific Method: At the inception of Operations Research, all those engaged in the activity were scientists and engineers. The only approach to investigation with which theses men were familiar was the scientific method, and that is what they brought to bear on all problems studied .Thus, the application of scientific method, not in laboratory equipments, but in solving management and administrative problems has been and ever will be a distinguishing characteristic of Operations Research. As a matter of fact, that the strength of OR is in it's methodology and it's dedication to solving real problems confronting decision-makers.

Use of Multi-disciplinary Teams: During the war, scientists and engineers selected from diverse disciplines formed Operations Research groups which investigated a variety of problems. The use of interdisciplinary teams provided the synergy needed to deal with the complex problems often encountered in the management of large organized systems composed generally of men and machines.

Adaptation of Systems Approach: This was the approach used by the pioneers of Operations Research in their investigations and has been the approach used ever since by Operations Research scientists in finding solutions to the problems confronted by decision makers in the management of organized systems composed of men and machines. As argued by Chacko in Idama (1999), lack of proper understanding of "the interaction of the elements is what makes outcomes such as safety-unknowable in advance." The systems approach, the attempt to understand the interactions among the variables, is a hallmark of the OR approach to problem solving.

Operations Research Techniques: In OR, managerial problems are approached in the context of modules (Olokoyo, 2001). A model is an imitation of reality, whose purpose is to understand a complex problem though a simpler, less expensive, and less cumbersome object. As argued by Taha (1997), the optimization problem posed by these models gives rise to a variety of solution methods, each designed to account for the special mathematical properties of the 
model". The most prominent and successful of these techniques is Linear Programming which has the following definitions:

Linear Programming (LP) involves the planning of activities to obtain an optimal result (Hillies and Lieberma, 1995).

LP is a systematic procedure for finding the optimal plan, or program for a given set of conditions (Upton, 1996).

LP is a mathematical modeling technique designed to optimize the usage of limited resources (Taha, 1997).

LP is a mathematical technique which is useful when one is in a situation that requires finding out the best use of an organizations limited resource (Agbadudu, 1987).

LP is a mathematical technique which involves the allocation of limited resources in an optimal manner, on the basis of a given criterion of optimality.

LP is conveniently used when more than two constraints in terms of input factors are introduced in a problem (Frankel, 1990).

LP is the name given to the method of optimizing a linear function of several variables subject to linear constraints with the algorithm used based on simplex method (Buchamann and Peter in Mbamo, 1995).

LP is not an optimizing technique in which the functions are all linear, real life costs are not necessarily linear and therefore LP cannot be used in such situations (Harper in Wosi, 1997).

In summary, LP is a procedure by which choice can be made of the best set of activities in which to engage, when the possible activities from which to choose are very numerous given a correspondingly scarce resource.

\section{Contributions of Operations Research}

Testimonials: Leading executives at organizations worldwide have used Operations Research Techniques to make better decisions. Here are testimonials from some OR satisfied customers:

i. Robert C. Wright- Chairman/CEO, National Broadcasting Company: "Operations Research Techniques have given us a significant competitive advantage during the 'upfront market'. All the hard work and creativity that went into this project definitely has paid off. In fact, these new systems have an impact of over $\$ 50$ million in annual revenues and have greatly boosted the productivity of the NBC sales staff. Our network sales organization has seen firsthand how OR methodologies can revolutionalize how we work."'(www.theorsociety.com)

ii. Robert L. Crandall- Chairman, President/CEO of AMR and American airlines: I believe that yield management (an OR driven process) is the single most important technical development in transportation management since we entered the era of airline deregulation in 1979. The development of yield management was a key to American airline's survival in the post-deregulation environment. Without yield management, we were often faced with two unsatisfactory responses in a price competitive market place. We could match deeply discounted fares risk diluting our entire inventory, or we could not match and certainly lose market share. Yield management gave us a third alternative- match deeply discounted fares on a portion of our inventory and close deeply discounted inventory when it is profitable to save space for later booking higher value customers. By adjusting the number of reservations which are available to these discounts, we can adjust our minimum available fare to account for differences in demand. This creates a pricing structure which responds to demand on a flight-by-flight basis. As a result, we can more effectively match our demand to supply.

iii. Launnny Steffens- Vice-Chairman, Meerrill Lynch and Company: "The decision to implement integrated choice was an unprecedented change in strategy for us. Operation Research provided the modeling and analysis that enabled me and my executive management team too better understand the revenue risks. The overall risk ranged from $\$ 200$ million to $\$ 1$ billion in revenue. This is the kind of thing that kept me up nights! The risks were also very critical at the individual financial Advisor levels."

iv. Robert Ritchie- President and CEO, Canadian Pacific Railroad: "We have developed the best scheduled railway model in the industry. The result has been huge gains in efficiency and productivity and better service for our customers. Our job however is never over. I learned that an awful lot of opportunities still exist for us in the area of revenue management and contract negotiations. We are continuously looking for new ways to improve, and OR is going to be crucial to our success in the future.

\section{OR inside Your Shopping}

When you hand over your reward card at a supermarket checkout, the store captures details of exactly what you bought and when you bought it. Very detailed and potentially valuable information, which can be used to help the supermarket give you better service by ensuring that the things you want to buy are in stock when you want to buy them and to keep costs down by making orders placed with suppliers more accurate and thus minimizing the amount of food unsold at the sell-by date.

\section{OR inside Satnav (Satellite Navigation)}


Satellite navigation systems in vehicles allow the driver to enter destination details into a small on-board computer that calculates the optimum route. In just a few seconds the route is downloaded and clear verbal turn by turn instructions are provided throughout the journey and a route map is also displayed. The more sophisticated systems constantly monitor the journey and provide the driver with delays and instantly recalculate the new optimum route. Satnav systems work by having OR inside: they use optimization algorithms and heuristic techniques to calculate routes along known highways.

\section{Future of Operations Research}

The future of Operations Research is bright (Alexander H.G. Rinnooy Kan, (www.sciencedireect.com). According to Russell L. Ackoff(1979), "OR is in a mess." Whatever be his reason(s) for this statement, it should be taken as a challenge to ensure that, Operational Researchers formulate their ideals explicitly, pursue them effectively and do so in a way that brings satisfaction to all those who are involved and affected by such a pursuit.

Davis R.A and Schamberg R. (1959) reported that "the ever expanding scope of OR activity in the aircraft, missile and spaceflight fields is traced, beginning with the search for optimal employment of existing military aircraft in World War II. The most promising area for future application of OR is believed to be the search for preferred operational concepts in an era when an advanced technology renders feasible a greater variety of expensive systems than can generally be developed and procured with available budgets."

\section{The Learning Organization}

The "Learning Organization" is a term introduced by Peter Senge. It is a style of management that has been advocated in the USA by the MIT Dialog Project. It involves restructuring the business to fit a post modernistic philosophy (The work-place is considered to be an organic, living being and management should be by consensus.) If truly is a "learning organization" the whole business learns as it progresses.

"In summary, a learning organization is a business in which the whole staff form a team, all voices are heard, dissidents are included (it is assumed that they oppose management decisions because they have good reason, not because they are bloody-minded) and new ideas can be identified and adopted if they are good, so the organization learns."(www.orsnz.org.nz)

Thus the future of OR is greatly brightened when business organizations seek to become "learning organizations". There will be a conscious collective mindfulness which OR seeks. For in considering new ideas, organizations move from 'a point of view' to 'viewing a point'.

\section{Conclusion}

Operations Research is hard work. It cannot be practiced by lazy people. There is no short cut to OR. Its meticulous methodology must be studied, understood clearly and followed. However, it is rewarding to study and employ OR. In today's e-business and deep computing, there is a conviction that organizations that make the best use of Operations Research are those that will be most successful. Thus, developing countries like Nigeria must be made to realize that their most needed tool of change lies in their use of Operations Research.

\section{REFERENCES}

[1] Ackoff R. (2003), Redesigning Society, Stanford University Press, USA.

[2] Abgadudu A.B. (1987), Mathematical Methods in Business And Economics, Lagos University Press, Lagos, Nigeria

[3] Alexander H.G. Rinnooy Kan (www.thesciencedirect.com)

[4] Bamo P.E (1995), Automated Linear Programming, Unpublished, B.Tech; Operations Research

[5] Dissertation, Department of Statistics/Operations Research, Federal University of Technology, Yola.

[6] Britannica (1981). The New Encyclopedia Britannica. Helen Hemmingway Benton Publishers, 13, p.594.

[7] Bronson R. and Naadimuthhu G. (1997), Shaum's Outline of Theory and Problems of Operations Research, Mc-Graw Hill, New York.

[8] Davis R. and Schamberg R. (1959), The Future of Operations Research In The Aircraft and Space Systems Industry.

[9] Frankel E.G. (1990), Management of Technological Changes, Kluwer Academic, Graw-Hill, New York.

[10] Gupta P. (1984), Introduction to Statistical Methods, Prentice Hall, New Delhi.

[11] Hillier F.S and Lieberman G.J (1995), Introduction to Operations Research, Mc-Graw Hill, New York.

[12] Hillier F.S and Lieberman G.J (2001), Introduction to Operations Research, Mc-Graw Hiill, New York.

[13] http://curiouscat.net- Curious Cat Management Improvement Library.

[14] http://www.innforms.org -Operations Research.

[15] http://www.mit.edu -Operations Research Center.

[16] http://www.orgnz.org.nz-Boland

[17] http://www.orie.cornnell.edu -School of Operations Research and Information Technology.

[18] http://www.or.ncsu.edu - NC State University: Operations Research 
[19] http://www.orsoc.org.uk - The OR Society.

[20] http://www.sciencedirect.com - Science Article.

[21] http://www.scienceofbetter.org - Operations Research.

[22] http://stinet.dtic.mil - Get Record and Metadata.

[23] http://www.theorsociety.com -

[24] http://www.wikipedia.com - The Free Encyclopedia.

[25] Idama A. (1999), Understanding Operations Research, Paraclete Publishers, Yola.

[26] Kalavathy S. (2000), Operations Research, Vikas Publishing House PVT Ltd, Chennnai.

[27] Launny Steffans (www.scienceofbetter.org)

[28] Mc-Graw Hill Encyclopedia of Science and Technology (1997), Vol. 10, $8^{\text {th }}$ ed., Lakeside Press, Pennsylvania.
[29] Mogono M. (1991), How To Make Bigger Profits, Graham and Trotman Ltd, London.

[30] Olokoyo S. (2001), Quantitative Techniques for Business Decisions: An OR/MS Approach, Lawal Graphic Prints, Kaduna-Nigeria.

[31] Robert C. Wright (www.scienceofbetter.org)

[32] Robert Ritchie (www.scienceofbetter.org)

[33] Robert L. Craudall (www.scienceofbetter.org)

[34] Taha H. (1997), Operations Research - An Introduction, Prentsice Hall Mc, USA.

[35] Russell L. Ackoff (1979), Resurrecting The Future of Operations Research (www.curiouscat.net)

[36] Wosi B. (1997), LP Approach To Resource Allocation, Unpublished, B.Tech; Operations Research Dissertation, Department of Statistics/Operations Research, Federal University of Technology, Yola, Nigeria. 